\title{
IMPLEMENTATION OF ELECTRONIC TEXTBOOKS IN SECONDARY SCHOOLS: WHAT TEACHERS NEED
}

\author{
Sarah Mello and Machdel Matthee \\ Department of Informatics, University of Pretoria, South Africa
}

\begin{abstract}
E-textbooks are gaining momentum in the education systems and are used for teaching and learning. Teachers are often reluctant to accept and use these technologies in the classroom, despite the numerous advantages thereof. In environments where the use of e-textbooks are mandatory, such reluctance often manifests as using the software in a superficial way and job dissatisfaction. The objective of this study is to determine the needs of teachers when implementing e-textbooks. An interpretive case study was conducted at a secondary school in South Africa. 'Interviews were conducted with 14 teachers. The findings were used to enhance an existing 'needs of using e-textbooks perception scale'. Apart from the usability and functionality features of e-textbooks, this study highlights the need of teachers for 1) adequate and timely training, 2) having no learners in their classrooms without a tablet or mobile device, 3) the ability to choose the textbooks themselves, and 4) the need to communicate their requests regarding the software and functionalities with the service provider.
\end{abstract}

\section{KEYWORDS}

Mobile Learning, E-textbooks, Tablet PC, Teachers' Needs

\section{INTRODUCTION}

The problem identified was that teachers are often reluctant to use e-textbooks in their classrooms as another method of presenting learning material to their learners. E-textbooks nowadays are available for use by learners and teachers in classrooms. However, it appears that teachers who know little about technology are not willing to use technology (in this case e-textbooks) in classrooms (Wang, Hung, Hsieh, Tsai and Lin, 2012). Sometimes teachers feel that they were not consulted in the decision to implement technology in the classroom. For example, Weilbach and Matthee (2015) report that teachers felt that the decision to use e-textbooks was not theirs.

Teachers could be unwilling to use these e-textbooks as they are comfortable with using traditional textbooks. Other reasons for this resistance include lack of proper infrastructure such as hardware and software (Buabeng-Andoh, 2012), not having the required training on how to use e-textbooks, limited time to assess the e-textbooks and produce good learning material and the unavailability of funds from schools to buy e-textbooks (Johnson \& Buck, 2014).

E-textbooks are a recent intervention in South African schools and are being introduced in a number of schools in South Africa (ITWeb, 2012). In addition, many South African schools are now adding Tablet PCs in their classrooms and this will affect learners as well as teachers (South Africa.Info, 2013). However, teachers are reluctant to adapt their current teaching methods and do not necessarily want to embrace the technology (Weilbach \& Matthee, 2015). Eicker-Nel and Matthee (2014) investigated "the adoption of tablet based e-textbooks in a South African private school". They found that the learners found that the tablets and e-textbooks were advantageous because of lighter backpacks, having everything in one place, and no excuses of forgotten printed textbooks. However, they emphasized the importance of proper infrastructure and teachers needing to acquire new teaching skills. Lin, Liu and Kinshuk (2015) investigated "teachers' needs when using e-textbooks in teaching". They suggested a number of needs pertaining to the textbook itself (discussed in more detail in section 2.4 below). From the studies mentioned above, it seems that there are more aspects to consider apart from the functionalities of the textbook itself. 
This study aimed, through a qualitative detailed investigation, to add to the study of Lin, Liu and Kinshuk (2015) by identifying the needs of teachers regarding the use of tablet-based e-textbooks in classroom. The researchers used the UTAUT model of Venkatesh, Morris, Davis \& Davis (2003) to guide the interviews with focus on the constructs performance expectancy, effort expectancy, social influence and lastly facilitating conditions. The constructs 'Facilitating conditions' specifically, shed light on additional needs of teachers. The research question is therefore: What are the needs of teachers regarding the implementation of e-textbooks in the classroom?

This study focused on a specific e-textbook platform on tablet PCs in one particular private school in South Africa. This paper contributes to mobile learning by providing an understanding of what teachers need when using e-textbooks in the classroom. The needs identified can be used as guidelines by principals, teachers and service providers when the school(s) introduces e-textbooks as a teaching tool that both learners and teachers use daily.

\section{LITERATURE}

According to De Luna (2015), there is a transition in the publishing industry due to e-textbook technology's impact on education worldwide. $\mathrm{Gu}, \mathrm{Wu}$ and $\mathrm{Xu}$ (2015) wrote that devices such as tablet PC, smartphones, e-book readers and iPads are rapidly dominating education systems worldwide. Book publishers have recognized the adoption of these devices and are now offering digital format textbooks called electronic books or e-textbooks (Rockinson-Szapkiw, Courduff, Carter and Bennett, 2013). Similarly, to printed textbooks, e-textbooks contain materials that are used in the classroom.

This sections discusses the previous researches that were done that focused on defining e-textbooks, identifying its advantages and disadvantages in education setting, technology acceptance in schools and the needs assessments that can help teachers implement e-textbooks in classrooms.

\subsection{E-textbooks and their Advantages and Disadvantages}

Embong, Noor, Hashim, Ali and Shaari (2012) defines e-textbooks as any published materials such as books or journals which can be read using a digital device such as mobile phones or tablets and are not in the form of hardcopy. E-textbooks enable learners to access printed textbook in an interactive way (Al-Mashaqbeh, 2015). Patel and Morreale (2014) wrote that even though electronic books provide these features and opportunities, they might not be used due to the users not knowing how to navigate and utilize them.

The advantages of electronic books include easier delivery and cheaper purchase. Back-up and storage are simpler with e-textbooks. Another advantage of electronic books is that they are cheaper than the printed textbooks (Patel \& Morreale, 2014). Some studies show that students and teachers still prefer printed textbooks rather than electronic books (Dobler, 2015).

A disadvantage that Embong, et al. (2012) pointed out was that even though there are a number of devices that can be used to read e-textbooks, some provide limitations to the users. Other limitations and disadvantages suggested by Mehdipour \& Zerehkafi (2013) are that some devices do not have sufficient storage space to store the number of e-textbooks that the user wants or requires and some classrooms do not have enough power outlets. They further emphasize that training is vital to teachers before and when using e-textbooks in classrooms. Furthermore, even when training is provided to teachers, some may still need more training; meanwhile, they cannot use e-textbooks to teach in class.

\subsection{Teachers Acceptance of Technology and E-textbooks in Education}

There are factors that influence the acceptance and rejection of using technology in classrooms by teachers, and these factors include teachers' attitude, beliefs and feelings (Alfahad, 2012). Buabeng-Andoh (2012) and Koksal, Yaman and Saka (2016) identified factors that they think prevent teachers from integrating technology in their classrooms. These factors are the teachers' attitude towards technology, their gender and age, technical support factors, accessibility and computer competency. 
According to Alfahad (2012), these factors are divided into two categories, which are internal factors and external factors. Alfahad (2012) and Aflalo (2014) wrote that some of the internal factors that influence technology's acceptance and use include perceptions, fears and beliefs of teachers. In short, these factors are the way teachers judge themselves when it comes to introducing something new to their teaching processes and the confidence they have once they have finished the training courses (learning how to use the technology introduced in school for teaching) (Alfahad, 2012; Blackwell, Lauricella, Wartella and Robb, 2013). Hence, if the teacher feels that they have acquired enough knowledge about the technology and they feel confident to use it, then they will integrate it into their teaching toolkits (Alfahad, 2012). However, it is better to introduce change to educators in small chunks so that they feel confident enough or encouraged to study the technology and therefore learn the whole thing and implement it (Alfahad, 2012).

The external factors that can influence the adoption of technology by teachers include gender and age of the teacher, the support that the school can offer to teachers and the size of the class (Alfahad, 2012) and teaching experience (Bataineh \& Anderson, 2015; Park, Byun, Sim, Han \& Baek, 2016). Furthermore, the lack of teacher's computer knowledge and use influences the use of information technology in teaching (Buabeng-Andoh, 2012). In any case, technology in education is an innovation and its success depends on the acceptance of it by teachers as well as their students (Ifenthaler \& Schweinbenz, 2013).

A study by Ifenthaler and Schweinbenz (2013) considered teachers' perspectives regarding the acceptance of the tablet PC for teaching in classroom, using the UTAUT model. They pointed out that teachers and students play a vital role in the success of tablet PC integration. The research approach that they used was qualitative research. They used the UTAUT model. They made use of all four constructs of the model which are performance expectancy, effort expectancy, social influence and facilitating conditions and added behaviour intention as well as use behaviour from the TAM.

The interview questions they asked the teachers were in-line with the UTAUT model and the teachers' attitude towards tablet PC. What they found on the performance expectancy construct was that a small number of teachers believed that tablet PCs might enhance "learning and instruction". Although they have seen tablet PC's potential, they did not have any idea how they could implement it as a teaching method. Age and gender played a role in their study (as part of the facilitating conditions construct).

Moving closer to e-textbooks, Eicker-Nel and Matthee (2014) investigated "the adoption of tablet based e-textbooks in a South African private school" using Activity theory. The data collection method they used was interviews using an interpretive case study. Their sample consisted of learners and teachers from the same grade (Grade 10) and the same school in South Africa.

They found that the learners considered tablets and e-textbooks as advantageous: tablets were light in weight, easy to use compared to printed textbooks, and easy to access due to being stored in one place, unlike when they forgot a printed textbook at home. Even though there were some advantages that tablets and e-textbooks brought, there were problems experienced by both learners and teachers. These problems included too many files and applications in different locations in the tablets, making it difficult to access some at the same time, tablets charging problems, difficulties when moving from one page to the next and trouble reading from the tablets. In the conclusion to their study, they wrote that there were a few things required when e-textbooks are introduced, which can also influence the adoption of e-textbooks. These are infrastructure that can provide e-textbook platforms and teachers needing to acquire new teaching skills.

Similar to the study by Ifenthaler and Schweinbenz (2013), this study employs the UTAUT theory (explained in the next section) to guide the study.

\subsection{Unified Theory of Acceptance and use of Technology (UTAUT) Model}

The purpose of the UTAUT model is to define the intentions of the user to utilise technology and extend the behavioural usage of technology (Alshehri, Drew and AlGhamdi, 2012). UTAUT consists of four important constructs. They are: performance expectancy, effort expectancy, social influence and lastly facilitating conditions (Alshehri et al., 2012). According to Alshehri et al. (2012), these constructs are used to determine behaviour and usage intentions. The other four constructs are used to influence the impact of the first construct (Alshehri et al., 2012). These other constructs are gender, age, experience and voluntariness of use (Alshehri et al., 2012). 


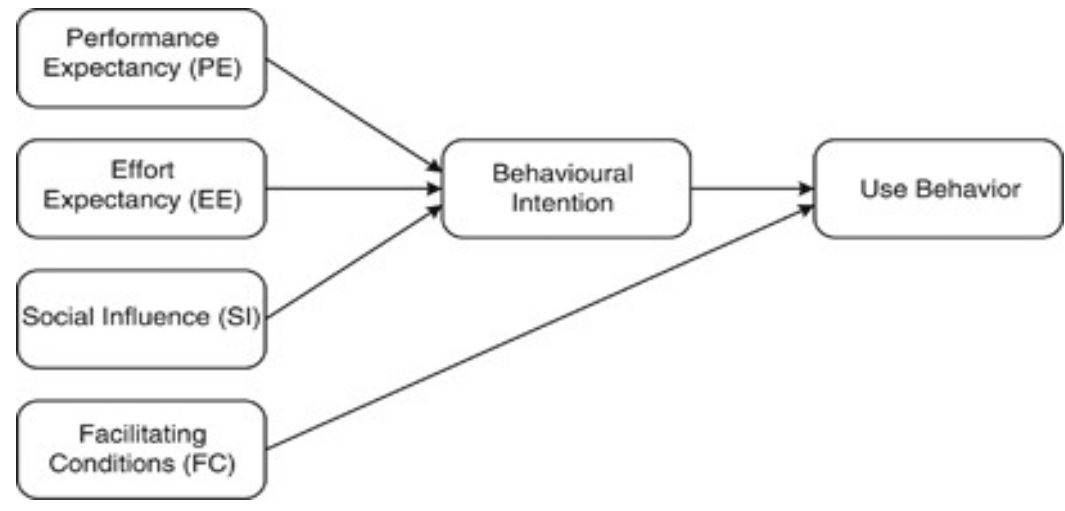

Figure 1. Unified Theory of Acceptance and Use of Technology (Venkatesh et al., 2003)

The four main constructs are defined as follows (Alshehri et al., 2012; Williams, Rana \& Dwivedi, 2015):

- Performance expectancy, which "is the degree to which an individual believes that using the system will help him or her to attain gains in job performance".

- Effort expectancy, which "is the degree of ease associated with use of the system".

- Social influence, which "is the degree to which an individual perceives that important others believe he or she should use the new system".

- Facilitating conditions, which "is the degree to which an individual believes that an organisational and technical infrastructure exists to support use of the system".

\subsection{E-textbooks Needs Assessment Instrument}

Lin, Liu and Kinshuk (2015) constructed the "needs of using e-textbooks perception scale" that would assist teachers in implementing and using e-textbooks in schools. Their study involved 415 teachers from 22 schools responding to a questionnaire and they interviewed five teachers who were known to be experts in the field of using technology in school. Out of the 415, only 378 participants' responses were usable for the study. They used a quantitative research approach.

Their work established three "needs of using e-textbooks perception scale" which are "to support teaching activities, to support reading and presentation and to support learning activities". They explained the first need of teachers as functions such as pushing of resources, giving quizzes, and the ability to update content when using e-textbooks. The second need was described as the need to provide teachers e-textbooks that have, to name a few, hyperlinks and functionality to change fonts and size. The last need was explained as the need to highlight information on the e-textbooks and "provide parent management interface".

According to their study, this "needs of using e-textbooks perception scale" were not based on or affected by gender and age. However, the level at which teachers teaches played a role in two of the three needs categories namely "needs of using e-textbooks perception scale" and "support teaching activities and support reading and presentation".

\section{METHODOLOGY}

This is a qualitative research study. The reason for using this method was that it allows the researchers to conduct a case study with the use of interviews to help determine and understand in-depth the teacher's perceptions with regard to the use of e-textbooks in classrooms for teaching purposes. There are several methods used in qualitative research and they are grounded theory, case study and action research (Myers, 2013). A case study methodology was chosen to be suitable for this study. The objective of a case study is to "illustrate a principle or a particular point that the instructor wishes to make" (Myers, 2009).

A sample is defined as "a subset of a population selected for measurement, observation or questioning, to provide statistical information about the population" (Boundless, n.d). The population for this study consisted of only the teachers who are using the e-textbooks for teaching purposes in the classroom. The participants in 
this study were 14 secondary-level school teachers at a school in Gauteng. Of the 14 participants, there were 10 male teachers and 4 female teachers, with various levels of teaching and e-textbooks experience. The school that interviews were conducted at is a private school and it has grade RR up to grade 12 . Secondary school is from grade 8 to grade 12 .

Recently a private company (EduX) launched a tablet PC based e-textbook platform at specific schools in South Africa. Its purpose is not to change the traditional learning process which it states is an environment in which the teacher is in control. It supports a blended learning process whereby traditional teaching is mixed with electronic learning. It provided tablet PCs, e-textbooks, tablets applications and storage to learners and teachers. It also provided the school with miEbooks application which is an e-textbook reader. The application provides a number of activities that both teachers and learners can use for learning. The functions are 1) the teachers can push homework, classwork, assessments, tests and notes to learners' resource library, 2) teachers can check learners' participation when using e-textbooks, 3) they can also download videos and push them to learners' resource library, 4) mark assignment and tests and 5) within an e-book, the user (teacher and learner) can highlight or underline information and make notes.

Interviews were used for data gathering. Myers (2013) wrote that the understanding of social context of people in terms of their "roles and situations" can be obtained with the use of interviews. The researchers made use of the semi-structured interview method, the reasons being that it allows the researchers to go through pre-determined questions and add other questions as the interview proceeds (Myers, 2013). It also allows the interviewee to pose questions to the interviewer, creating a conversation between the two and the questions asked by the interviewer can be open-ended. The only personal data that the researchers asked participants were their gender, age, years of experience and subject they taught. Each interview lasted for approximately 20 minutes. Most of interview questions were based on the constructs of the UTAUT model as shown in Figure 1 above. The interviews were all face-to-face and responses received were text-based data transcribed from 12 recorded and two unrecorded interviews.

The qualitative data analysis technique that was used is thematic content analysis. Braun and Clark (2006) define thematic content analysis as "a method for identifying, analyzing and reporting patterns within data". Alhojailan (2012), Moldavska and Welo (2017) and Mayring (2014) stated that there are two types of thematic content analysis, that is, deductive and inductive analyses. A deductive approach is a process of testing an existing theory that was used and tests if the theory can produce the appropriate resulting different situations (Alhojailan, 2012). He further defines the inductive approach as it does not follow any theory and that at the beginning of a research study observations have to be collected and there is no theory that is used to create questions for the study. This study focused on the deductive approach since the constructs of the UTAUT model were used to analyze the data.

\section{FINDINGS}

From the interviews analyzed, the fourth construct of the UTUAT model which is facilitating condition identified three themes through thematic contact analyses. The themes are Tools, Training and Support (from colleagues and from technicians). Facilitating Conditions was used to investigate the things that teachers need so that they can accept and use e-textbooks in the classroom. Literature findings identified three needs which were found from a study by Lin, et al. (2015). The needs they identified are detailed in Section 2.4 above. From the interviews findings, the needs were identified from answers that were related to infrastructure and training. The infrastructure in this study is software and hardware that the learners and teachers use daily when using e-textbooks. When it comes to software, there are different operating systems that are used and among them there is one that performs better than others. Therefore, the school needs to look at what works better and use that. Regarding hardware, for teachers the devices such as laptops, projectors and tablet PCs are available but the problem is when a learner does not have the device, it disrupts the use of e-textbooks.

Furthermore, there were three needs that were identified from the literature findings and another four found from the interviews. Some of these needs were identified by the themes found under this construct, which are Tools, Training and Support. The tools that they are using, which are laptops, tablet PCs and overhead projectors, according to participants are good tools for using e-textbooks in the classroom. Training seemed to be a problem, as some participants mentioned that they never had training when they joined the school; therefore, they are learning in classrooms as they use e-textbooks and tablet PCs and they struggled in the beginning to use e-textbooks. However, over time when they used them frequently and got training from their 
peers, it became easier for them to use the technologies. Furthermore, there was a complaint from some of the respondents that the training they receive from EduX is sometimes excessive and therefore they struggle to grasp what was taught; thus, they will not implement what they were taught. Therefore, the first need that was identified was the need for appropriate training before using the e-textbooks.

The second need that the researchers identified from the interviews analysis was the need for accessible devices for all learners. Some participants mentioned that there are several learners without tablet PCs and that this affects the use of e-textbooks in the classroom and outside the classroom. They mentioned that there are a few reasons as to why some learners do not have tablet PCs and these reasons are that the tablet PC got lost, got damaged, or even got stolen. Some parents are unable to replace the e-textbooks immediately which affects learners' progress.

The third need identified from the interviews was the need to be able to choose the e-textbook that teachers wanted to use for their specific subject. One of the participants mentioned that they are unable to choose the e-textbooks they would like to use. This statement is supported by the response from a teacher from the Lin, et al. (2015) study. At the time of conducting this study, EduX had an agreement with only selected publishers, resulting in having only certain textbooks available. It also implies that some of the e-textbooks might not be good to use for certain subjects.

A tablet PC has limited space for storing applications and other forms of information. One participant mentioned that there are some functionalities for which they do not have access to on the EduX platforms. Access to these functionalities would assist them in performing certain functions without relying on the EduX personnel to assist them. He further gave an example of the functionality which he would like the teachers to have namely permission to remove old resources that they no longer use. Furthermore, he elaborated that it was communicated to EduX that there are old videos that were still on the devices that they had requested to be deleted. This implies that teachers do not have all the permissions they may need to do certain things. The information that cannot be deleted on devices takes up space for other new resources to be loaded. The need for access to all the functions that teachers need was identified as the fourth need. The findings from this construct influence Use Behaviour in a positive way. The tables below show a comparison of the findings from the needs assessment perception scale and the findings from this study.

The NUEPS (Needs of using e-textbooks perception scale) is given below in table 1 .

Table 1. Needs of using e-textbooks perception scale

\begin{tabular}{ll}
\hline NUEPS & Description \\
\hline Supporting teaching Activities & $\begin{array}{l}\text { Teachers need to be provided with the functions such as } \\
\text { pushing of resources, giving quizzes, and the ability to } \\
\text { update content when using e-textbooks. Another function } \\
\text { that they need is the ability to share group learning outputs } \\
\text { as well. }\end{array}$ \\
$\begin{array}{ll}\text { Supporting features and functions } \\
\text { of Reading and Presenting }\end{array}$ & $\begin{array}{l}\text { The need to provide teachers e-textbooks that have, to name } \\
\text { a few, hyperlinks, to turn a page functionality to change } \\
\text { fonts and size. } \\
\text { The need to highlight information on the e-textbooks and } \\
\text { Interaction }\end{array}$ \\
\hline
\end{tabular}

Table 2. Needs of using e-textbooks identified in this study

\begin{tabular}{ll}
\hline NUEPS & Description \\
\hline The need for training. & $\begin{array}{l}\text { Teachers need to be provided with adequate and timely } \\
\text { training. }\end{array}$ \\
The need to accessible device. & $\begin{array}{l}\text { Having no learners in their classrooms without a tablet } \\
\text { or mobile device. }\end{array}$ \\
$\begin{array}{l}\text { The ability to choose the textbooks } \\
\text { Themselves. } \\
\text { textbooks that they think will be good for the subjects } \\
\text { they teach. } \\
\text { Teachers needs to be given an opportunity to voice out } \\
\text { their needs and requirements before the implementation } \\
\text { requests regarding the software and } \\
\text { functionalities with the service } \\
\text { provider. }\end{array}$ & $\begin{array}{l}\text { of e-textbooks. } \\
\end{array}$
\end{tabular}


In conclusion, many studies considered the implementation and use of e-textbooks at different levels of the education system. Moreover, they have been introduced in different countries, whether developed or developing countries. This study contributes towards existing research on e-textbook adoption by enhancing the NUEPS of Lin et al (2015). The NUEPS focuses on functionalities needed from textbooks in the learning and teaching process, whereas this study shows that needs pertaining to the learning environment of such an intervention cannot be ignored. Learning environment in this context refers to the enablers such as training, infrastructure, support and teacher control. The needs identified from both the literature and interviews findings can be helpful and if applied when e-textbooks are introduced in schools the integration of e-textbooks can yield positive results.

\section{CONCLUSION}

This paper provided some understanding as to what teachers go through during the introduction and implementation of e-textbooks in the classroom as a teaching tool. The needs identified in this paper can be helpful to schools and teachers during the implementation of e-textbooks. This paper can be extended to public schools and be useful for educators who are looking for tools for the classroom, for students and for continuing education and teachers with little technology experience.

There were some limitations to the study. These limitations were solely experienced during data collection. The first limitation was that the data were obtained from only one school. The researchers chose one school from many schools that are in South Africa in the province called Gauteng because the chosen school had already implemented e-textbooks and tablet PCs and both learners and teachers were using them. A better representation of teachers' views would have been obtained if more schools were involved.

Another limitation was the number of teachers who participated in the interviews. Only 14 teachers who were already using e-textbooks in the classroom from secondary level participated in the study and they were not chosen based on gender, age, experience or the subject they taught. The last limitation was the time that the researchers were allowed to conduct the interviews. The researchers were given lunch time to interview as many participants as they could and on average they managed to interview two teachers per day. Each interview lasted for approximately 20 minutes.

Apart from the usability and functionality features of e-textbooks, this study highlights the need of teachers for 1) adequate and timely training, 2) having no learners in their classrooms without a tablet or mobile device, 3) the ability to choose the textbooks themselves, and 4) the need to communicate their requests regarding the software and functionalities with the service provider. One of the biggest challenges identified by the teachers is the distraction of learners that use social media platforms during lessons.

If these needs are not addressed it can negatively impact the acceptance of e-textbooks on tablet PCs in the classroom by teachers. In general, though it seems that, apart from the functionalities of the e-textbook, by providing support, training and a good IT infrastructure, by allowing choices and interaction with the service provider, teachers will start finding e-textbooks a useful teaching tool.

\section{REFERENCES}

Aflalo, E. 2014. The invisible barrier to integrating computer technology in education. Journal of Education and Learning, Vol. 3, No. 2, pp 120-134.

Alfahad, F.N. 2012. Effectiveness of Using Information Technology in Higher Education in Saudi Arabia. 4th World Conference on Educational Sciences (WCES-2012). Barcelona, Spain, pp 1268-1278.

Alhojailan, A.M. 2012. Thematic analysis: a critical review of its process and evaluation. West East Journal of Social Sciences, Vol. 1, No. 1, pp 39-47.

Alshehri, M., Drew, S., \& AlGhamdi, R. 2012. Analysis of citizens' acceptance for e-government services: Applying the UTAUT model. IADIS International Conferences Theory and Practice in Modern Computing and Internet Applications and Research, pp 69-76.

Al-Mashaqbeh, I. \& Shurnan, M.A. 2015. The Adoption of Tablet and e-Textbooks: First grade core curriculum and school administration attitude. Journal of Education and Practice, Vol. 6, No. 21, pp 188-194. 
Bataineh, M., A., \& Anderson, S. 2015. Jordanian social studies teachers' perceptions of competency needed for implementing technology in the classroom. Contemporary educational technology, Vol. 6, No. 1, pp 38-61.

Blackwell, C.K., Lauricella, A.R., Wartella, E. \& Robb, M. 2013. Adoption and use of technology in early education: The interplay of extrinsic barriers and teacher attitudes. Computer \& Education, Vol. 69, No. 0, pp 310-319.

Boundless, Defining the sample and collecting data. [Online]. Available: https://www.boundless.com/sociology/textbooks/boundless-sociology-textbook/sociological-research-2/the-researchprocess-26/defining-the-sample-and-collecting-data-169-5911/ [Cited 27 March 2017].

Braun, V. \& Clarke, V. 2006. Using thematic analysis in psychology. Qualitative Research in Psychology, Vol. 3, No. 2, pp 77-101.

De Luna, T.P.S. 2015. Innovation in Education: Utilisation and Employment of e-Books in Philippine Educational institutions. International Journal of Information and Education Technology, Vol. 5, No. 4, pp 265-269.

Dobler, E. 2015. E-Textbooks: A personalized learning experience or a digital distraction. Journal of Adolesencent \& Adult Literacy, Vol. 58, No. 6, pp 482-491.

Education South Africa 2013. Striving for the highest - achieving educational excellence. [Online]. Available from: http://www.macmillan.co.za/news/media-coverage/3/public-school-goes-100-digital-e-books/1. [Cited 2 February 2017].

Eicker-Nel, S., \& Matthee, M. 2014. The adoption of tablet based e-textbooks in a South African private school. Proceedings of the e-Skills for Knowledge Production and Innovation Conference. Cape Town, South Africa, pp. 109-123.

Embong, A.M., Noor, A.M., Hashim, H.M., Ali, R.M. \& Shaari, Z.H. 2012. E-Books as Textbooks in the Classroom. Procedia - Social and Behavioral Sciences, Vol. 47, No. 0, pp 1802-1809.

Ifenthaler, D. \& Schweinbenz, V. 2013. The acceptance of Tablet-PCs in classroom instruction: The teachers' perspectives. Computers in Human Behavior, Vol. 29, No. 3, pp 525-534.

Johnson, G.E. \& Buck, G.H. 2014. Electronic Books versus Paper Books: Pre-Service Teacher Preference for University Study and Recreational Reading. International Journal of Humanities Social Sciences and Education, Vol. 1, No.8, pp 13-22.

Koksal, M. S., Yaman, S., \& Saka, Y. 2016. Analysis of Turkish Prospective Science Teachers' Perceptions on Technology in Education. Australian Journal of Teacher Education, Vol. 4, No. 1, pp 21-41.

Lin, Y., Liu, T. \& Kinshuk. 2015. Research on teachers' needs when using e-textbooks in teaching. Smart Learning Environment, Vol. 2, No. 1, pp 1-17.

Mayring, P. 2014. Qualitative content analysis: theoretical foundation, basic procedures and software solution. [Online]. Available: $\quad$ https://www.psychopen.eu/fileadmin/user_upload/books/mayring/ssoar-2014-mayringQualitative_content_analysis_theoretical_foundation.pdf. [Cited 30 August 2016].

Mehdipour, Y. \& Zerehkafi, H. 2013. Mobile Learning for Education: Benefits and Challenges. International Journal of Computational Engineering Research, Vol. 3, No. 6, pp 93-101.

Moldavska, A. \& Welo, T. 2017.The concept of sustainable manufacturing and its definitions: A content-analysis based literature review. Journal of Cleaner Production, Vol. 166, pp 744-755.

Myers, M.D. 2009. Qualitative Research in Business \& Management, London: Sage.

Myers, M.D. 2013. Qualitative Research in Business \& Management, Sage.

Park, H., Byun, S., Sim, J., Han, H. \& Baek, Y. S. 2016. Teachers' perceptions and practices of STEAM education in South Korea. Eurasia journal of mathematics, science \& technology education, Vol. 12, No. 7, pp 1739-1753.

Patel, H. \& Morreale, P. 2014. Education and learning: electronic books or traditional printed books? Journal of Computing Sciences in Colleges, Vol. 29, No. 3, pp 21-28.

Rockinson-Szapkiw, A.J., Courduff, J., Carter, K. \& Bennett, D. 2013. Electronic versus traditional print textbooks: A comparison study on the influence of university students' learning. Computer \& Education, Vol. 63, No. 0, pp 259-266.

Venkatesh, V., Morris, M.G., Davis, G.B. \& Davis, F.D. 2003. User Acceptance of Information Technology: Toward a Unified View. MIS Quarterly, Vol. 27, No.3, pp 425-478.

Wang, J.T., Hung, L.C., Hsieh, H.M., Tsai, J.T. \& Lin, I.H. 2012. Computer technology integration and multimedia application for teacher professional development: The use of instructional technology in the classroom settings. Procedia - Information Engineering Research Institute, Vol. 2, No. 0, pp 616-622.

Weilbach, L. \& Matthee, M. 2015. Using the PSIC model to understand change in an educational setting: the case of an e-textbook implementation. Twenty-Third European Conference on Information Systems. Münster, Germany, pp. 1-14.

Williams, M.D., Rana, N.P. \& Dwivedi, Y.K. 2015. The unified theory of acceptance and use of technology (UTAUT): a literature review. Journal of Enterprise Information Management, vol. 28, no. 3, p.443-488. 